\title{
Prediction of Liquid Slosh Damping Using a High Resolution CFD Tool
}

\author{
H. Q. Yang ${ }^{1}$ \\ CFD Research Corp., Huntsville, AL 35805 \\ Ravi Purandare ${ }^{2}$ \\ EV31 NASA MSFC \\ and \\ John Peugeot ${ }^{3}$ and Jeff West ${ }^{4}$ \\ ER42 NASA MSFC
}

\begin{abstract}
Propellant slosh is a potential source of disturbance critical to the stability of space vehicles. The slosh dynamics are typically represented by a mechanical model of a spring mass damper. This mechanical model is then included in the equation of motion of the entire vehicle for Guidance, Navigation and Control analysis. Our previous effort has demonstrated the soundness of a CFD approach in modeling the detailed fluid dynamics of tank slosh and the excellent accuracy in extracting mechanical properties (slosh natural frequency, slosh mass, and slosh mass center coordinates). For a practical partially-filled smooth wall propellant tank with a diameter of 1 meter, the damping ratio is as low as 0.0005 (or $0.05 \%$ ). To accurately predict this very low damping value is a challenge for any CFD tool, as one must resolve a thin boundary layer near the wall and must minimize numerical damping. This work extends our previous effort to extract this challenging parameter from first principles: slosh damping for smooth wall and for ring baffle. First the experimental data correlated into the industry standard for smooth wall were used as the baseline validation. It is demonstrated that with proper grid resolution, CFD can indeed accurately predict low damping values from smooth walls for different tank sizes. The damping due to ring baffles at different depths from the free surface and for different sizes of tank was then simulated, and fairly good agreement with experimental correlation was observed. The study demonstrates that CFD technology can be applied to the design of future propellant tanks with complex configurations and with smooth walls or multiple baffles, where previous experimental data is not available.
\end{abstract}

\section{Introduction}

Propellant slosh is a potential source of disturbance critical to the stability of space vehicles. The slosh dynamics are typically represented by a mechanical model of a spring mass damper. This mechanical model is then included in the equation of motion of the entire vehicle for Guidance, Navigation and Control analysis. The typical parameters required by the mechanical model include natural frequency of the slosh, slosh mass, slosh mass center location, and the critical damping ratio. During the 1960's US space program, these parameters were either computed from an analytical solution for a simple geometry or by experimental testing of sub-scale configurations. Our previous work [1] has demonstrated the soundness of a CFD approach in modeling the detailed fluid dynamics of tank slosh and

\footnotetext{
${ }^{1}$ Chief Scientist, CMB, 215 Wynn Drive, 5th Floor, and Senior AIAA member

${ }^{2}$ Aerospace Engineers, EV31, George C. Marshall Space Flight Center, MSFC, AL 35812, AIAA Member

${ }^{3}$ Aerospace Engineers, Fluid Dynamics Branch-ER42, George C. Marshall Space Flight Center, MSFC, AL 35812, AIAA Member

${ }^{4}$ Team Lead, Fluid Dynamics Branch-ER42, George C. Marshall Space Flight Center, MSFC, AL 35812, AIAA Member
}

1

American Institute of Aeronautics and Astronautics 
has shown excellent accuracy in extracting the mechanical properties for different tank configurations as a functiuon of fill level. The verification and validation studies included a straight cylinder against an analytical solution, and sub-scale Centaur LOX and LH2 tanks with and without baffles against experimental results for the slosh frequency, slosh mass and mass center. The study shows that CFD technology can provide accurate mechanical parameters for any tank configuration and is especially valuable to the future design of propellant tanks, as there is no previous experimental data available for the same size and configuration as the current flight designs.

Since the liquid oscillatory frequency may nearly coincide with either the fundamental elastic body bending frequency or the dynamic control frequency of the vehicle at some time during the powered phase of the flight, the slosh forces could interact with the structure or control system. This could cause a failure of structural components within the vehicle or excessive deviation from its planned flight path [2]. It is therefore necessary to consider means to provide adequate damping of the liquid motion and slosh forces and to develop methods for accounting for damping in the analyses of vehicle performance. Determination of slosh damping in a given tank configuration is a very challenging task. First, an analytical solution does not currently exist for the slosh damping due to high nonlinearity of the problem. While slosh frequency can be computed using linear potential theory, the damping physics involves the vorticity dissipation which requires full solution of the nonlinear Navier-Stokes equations. Previous investigations and knowledge of damping characteristics were all carried out by extensive experimental studies. Previously, four extensive experimental investigations have been carried out on viscous damping in a circular cylinder [3-6], and the damping values have been correlated to a functional form of:

$$
\gamma=C \sqrt{\mathrm{Re}}
$$

where Re is a dimensionless parameter analogous to an inverse Reynolds number [7]:

$$
\operatorname{Re}=\frac{v}{\sqrt{g R^{3}}}
$$

and $\mathrm{C}$ is a constant, $\gamma$ is the damping ratio, or the critical damping ratio of the amplitude of the free surface oscillation, $\mathrm{R}$ is the tank radius, $\mathrm{g}$ is the gravitational acceleration, and $v$ is the kinematic viscosity of the liquid.

Mikishev and Dorozhkin [6] proposed the following correlation from their tests [7]:

$$
\gamma=0.79 \sqrt{\operatorname{Re}}\left[1+\frac{0.318}{\sinh (1.84 h / R)}\left(1+\frac{1-h / R}{\cosh (1.84 h / R)}\right)\right]
$$

Where $\mathrm{h}$ is the liquid depth. For large depth of $\mathrm{h} / \mathrm{R}>1.0$, the above equation may be approximated by:

$$
\gamma=0.79 \sqrt{\mathrm{Re}}
$$

A similarly extensive but independent study by Stephens et al. [5] found a slightly different correlation:

$$
\gamma=0.83 \sqrt{\operatorname{Re}} \tanh \left(1.84 \frac{h}{R}\right)\left[1+2 \frac{1-h / R}{\sinh (3.68 h / R)}\right]
$$

When the liquid depth is large, equation (5) reduces to:

$$
\gamma=0.83 \sqrt{\mathrm{Re}}
$$


The above correlations have become the industry standard methodology to compute slosh damping value. For example, NASA Engineering and Safety Center (NESC) performed a comparison of the Orion Service Module slosh damping values with the Ares-1 launch vehicle slosh damping values and legacy slosh damping values from the Space Shuttle Program and the Apollo Saturn launch vehicle [8]. The empirically computed 1-g minimum slosh mode damping value from the above correlation for the Orion nitrogen tetroxide (NTO) oxidizer tank was found to be 0.0003 or $0.03 \%$. Likewise the empirically computed $1 \mathrm{~g}$ minimum slosh mode damping value for the Orion monomethyl hydrazine (MMH) fuel tank was found to be 0.0006 or $0.06 \%$. The NESC assessment team verified these empirical 1-g calculations of damping values.

It should be noticed that the above correlations are only for right cylinders and applicability to curved bottom tanks is questionable. With advancement of CFD technology, it is possible to predict slosh damping directly from first principles. As one may realize the critical damping ratio for practical partially-filled propellant tank is as low as $0.03 \%$ to $0.06 \%$, this gives rise to a great challenge for any numerical prediction using a CFD tool, as the numerical damping used to stabilize the solution could be higher than the viscous damping. Another challenge is the requirement to resolve thin boundary layers near the walls.

The objective of this effort is to improve our understanding of the physics behind slosh damping and to validate CFD extracted damping against experimental data using the same parameters. The study will take a fundamentally sound approach first with validations against experiments for the smooth wall cylindrical tank. High-order numerical schemes will be applied using a technique developed to estimate and reduce/remove the numerical damping from the solution. With the validated CFD model, we will then study the damping in the presence of a flat ring baffle which is a commonly used as means of slosh suppression.

\section{Computational Modeling Tool}

The computational software used to study the tank vertical sloshing phenomenon is the commercially available CFD-ACE+ program, which was originally developed by CFD Research Corporation (CFDRC), and is currently owned and distributed by ESI [8]. CFD-ACE+ is a multi-physics and multi-disciplinary simulation tool, and is especially suited for liquid slosh modeling.

CFD-ACE+ solves the Navier-Stokes equations in a Lagrangian-Eulerian frame. The continuity and momentum equation can be generally written as:

$$
\begin{gathered}
\frac{\mathrm{d}}{\mathrm{dt}} \int_{\forall} \rho \mathrm{d} \forall+\int_{\mathrm{s}}\left(\rho\left(\mathrm{v}-\mathrm{v}_{\mathrm{g}}\right) \cdot \mathrm{ds}\right)=0 \\
\frac{\mathrm{d}}{\mathrm{dt}} \underset{\forall}{\ln } \rho \phi \mathrm{d} \forall+\int_{\mathrm{s}} \rho \phi\left(\mathrm{v}-\mathrm{v}_{\mathrm{g}}\right) \cdot \mathrm{ds}=\int_{\mathrm{s}} \mathrm{q} \cdot \mathrm{ds}+\int_{\forall} \mathrm{S}_{\phi} \mathrm{d} \forall
\end{gathered}
$$

where $\phi$ are the Cartesian velocity components, $v$ is the absolute fluid velocity, $q$ the diffusive flux and $S_{\phi}$ are the volume sources. $\forall$ is the computational cell volume, $S$ are bounding cell surfaces, and $\mathrm{v}_{\mathrm{g}}$ is the grid velocity. If the grid is moving with time for the fluid-structure interaction problem, a space conservation law (SCL) is enforced during the grid deformation,

$$
\frac{\mathrm{d}}{\mathrm{dt}} \int_{\forall} \mathrm{d} \forall=\int \mathrm{v}_{\mathrm{g}} \mathrm{ds}
$$

Related to the present liquid free surface problem, CFD-ACE+ contains a Volume of Fluid (VOF) module which is designed for applications involving two immiscible fluids. In the current application, the first fluid is LH2, LOX, or water, and the second fluid is gaseous $\mathrm{H} 2, \mathrm{O} 2, \mathrm{He}$ or water vapor, respectively. In the VOF module, a single set of momentum and continuity equations is solved, but different property sets are defined for each fluid. The volume fraction of one phase (in this case the liquid phase) is tracked throughout the solution to determine which fluid occupies each computational cell at any given time. In cells containing both fluids, a special routine is used to locate the shape, location and normal of the interface. When surface tension force is significant, its effect is applied in a conservative form. For time dependent simulations such as the present tank under oscillatory force, a special second order algorithm is used to update the volume fraction in a cell from one time step to the next. A second order geometric reconstruction scheme for the interface representation is employed to track the interface. This unique reconstruction algorithm is currently available only for structured quadrilateral and hexahedral grids. It is due to this algorithm that the present CFD solution is capable of capturing and maintaining a sharp interface 
between the phases for very long period of time. The time step size is determined by the local Courant-FriedrichsLewy (CFL) number. Some of the validation studies and applications to space vehicle vertical and side sloshing can be found in references [9-11].

\section{Validation Study for Smooth Wall Slosh Damping}

We will use the experimental data correlated into the industry standard as our baseline validation. Figure 1 shows the experimental points we selected and the relationship to the correlation for the straight cylinders. The cylinder rdius varies from $3.8 \mathrm{~cm}$ to $45.7 \mathrm{~cm}$ and the contained fluid is water under normal gravity $(1 \mathrm{~g})$ condition. Due to the variation of the cylinder size, the damping ratio from experiments varies from $0.334 \%$ to $0.0776 \%$. Our goal is to determine the capability of the CFD solution in reproducing the damping trend and the accuracy of the prediction.

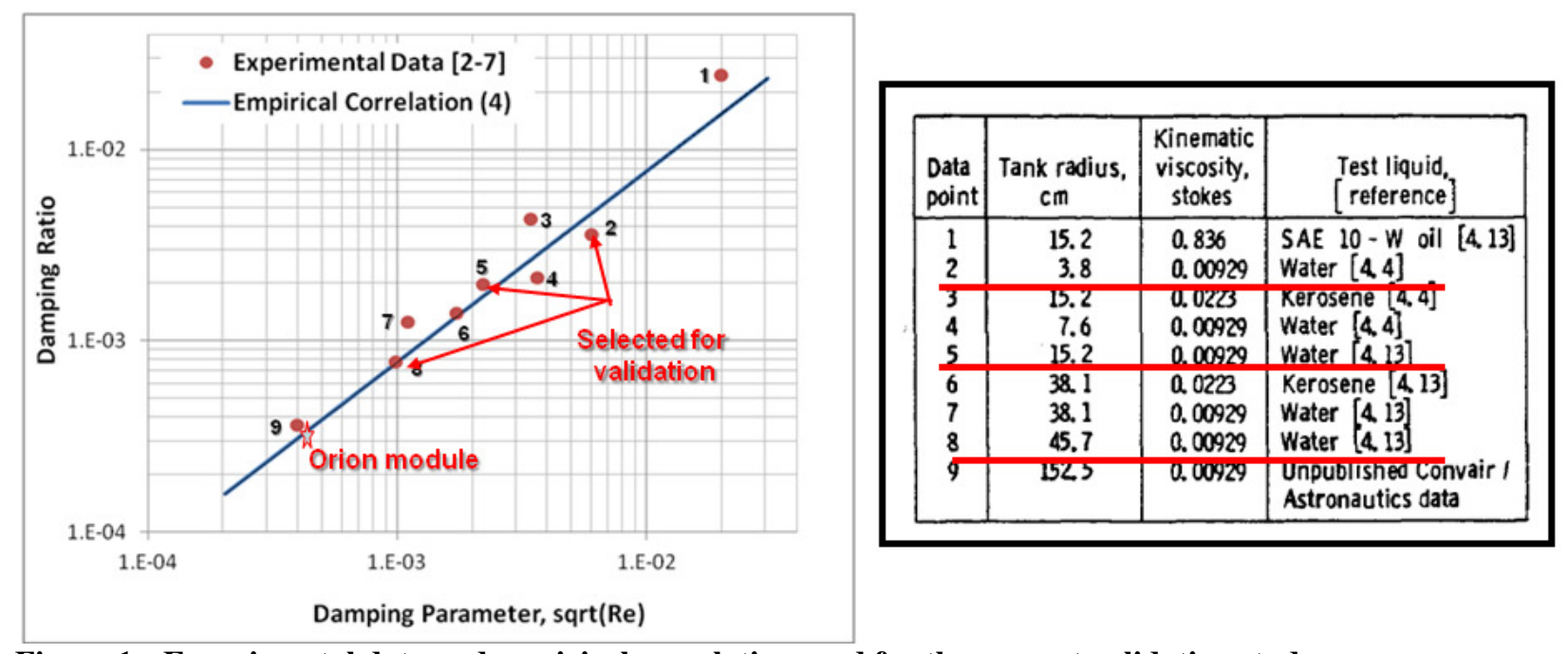

Figure 1. Experimental data and empirical correlation used for the current validation study

Simulation Model

The simulation model along with the computational grid are shown in Figure 2. Here the first data point (\#2) of a cylindrical tank with a radius of $\mathrm{R}=1.5$ " $(3.8 \mathrm{~cm})$ and height of $\mathrm{H}=12$ " is modeled. The tank has no internal obstruction and all the walls are smooth. The top of the tank is open to ambient and is set as fixed pressure boundary condition. All other boundaries are set as non-slip walls. Shown in Figure 2 is the coarsest mesh with a total of 40,000 hexahedral cells. There are 60 cells covering the whole tank diameter. This ensures that there will be at least 120 cells to resolve the first natural mode and 60 cells to resolve the second mode. A symmetry condition is assumed so that only half of the cylinder is considered. Butterfly grid methodology is used to avoid the singularity at tank center line, to give better uniformity in grid spacing, and to ensure resolution of wall shear stress. One can see from Figure 2 the grid is packed near the wall to resolve the boundary layer which contributes to slosh damping.

The initial liquid fill level is $2 \mathrm{R}$, therefore the simplified expression (4) can be used. To determine the slosh damping, an initial inclined surface is specified with a slope of $5.7 \mathrm{deg}$. The time step size is controlled by the CFL number, which is set at 0.1 . The maximum allowed time step size is $0.5 \mathrm{~ms}$. The temporal scheme is $2^{\text {nd }}$ order Crank-Nicolson, and the spatial scheme starts with $2^{\text {nd }}$ order central with $1 \%$ damping (meaning a hybrid with $99 \%$ of $2^{\text {nd }}$ order scheme and $1 \%$ the $1^{\text {st }}$ order upwind). As discussed in the following section, for finer mesh the solution instability forces one to use only the first order spatial scheme in velocity, although the solution of Volume-of-Fluid is still second order accurate in space.

$\underline{3.8 \mathrm{~cm} \text { Radius Tank with Water }}$

A typical time dependent mass center coordinate of the liquid mass inside the tank, computed by integrating the Volume of the Fluid value in each cell, is shown in Figure 3. As the tank is stationary and there is no energy input to the system, the liquid surface experiences free oscillation. The amplitude of successive slosh oscillations represented by the total mass displacement deceases because of energy dissipation (and due to numerical dissipation inherent in the CFD solution). The damping ratio can be computed as: 


$$
\gamma=\frac{1}{2 \pi} \ln \frac{A_{i}}{A_{i+1}}
$$

Where $\mathrm{A}$ is the mass center amplitude at $\mathrm{i}^{\text {th }}$ cycle. The extracted slosh damping is 0.0109 or $1.09 \%$, which is 3 times higher than the experimental data of $0.00334(0.334 \%)$ as seen from Figure 3. Indeed, it is very challenging to accurately predict the slosh damping using a CFD tool. This result indicates the requirement for grid refinement, which should reduce the numerical damping.
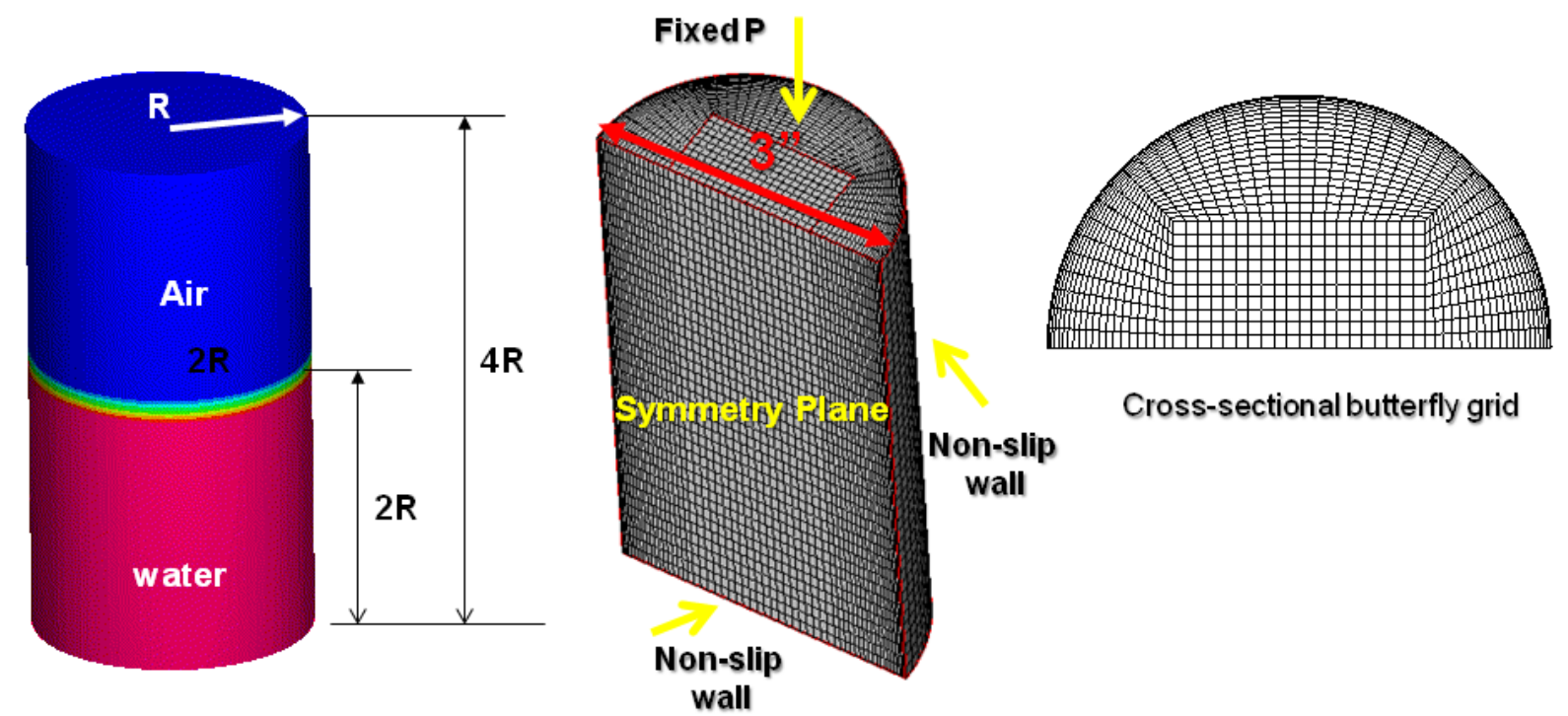

Figure 2. CFD model of a cylinder tank sloshing for comparison with experimental data

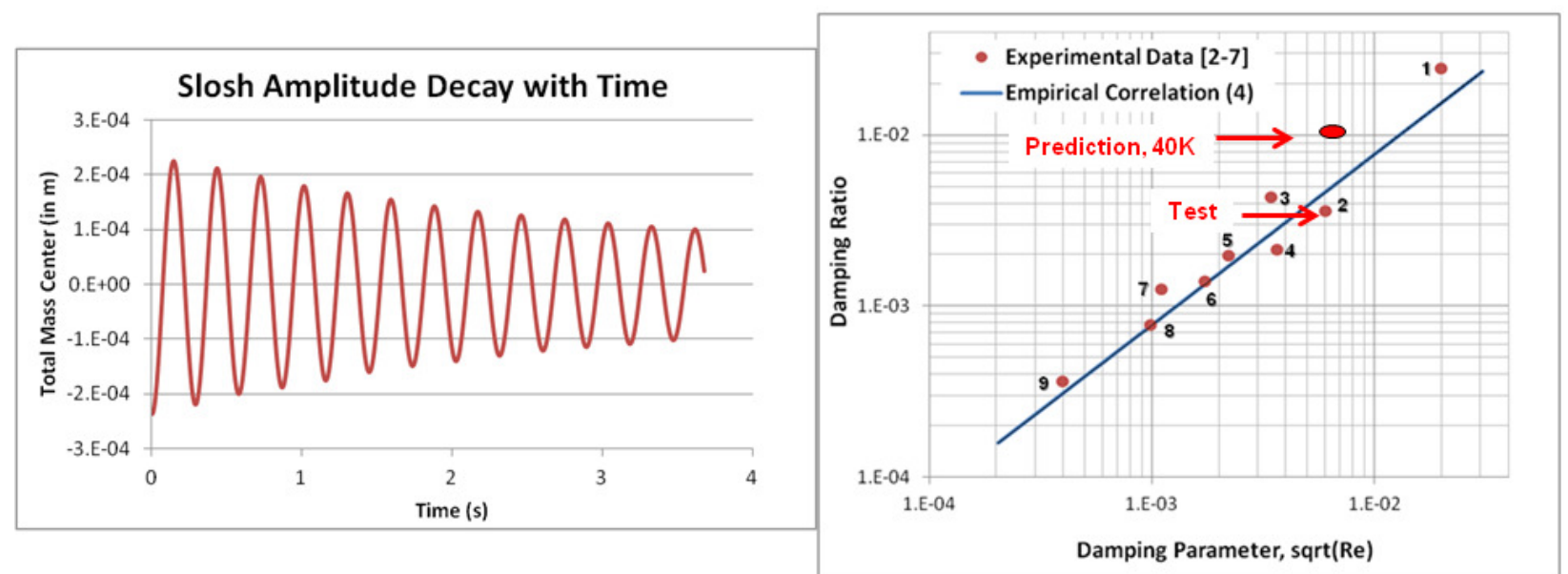

Figure 3. Total mass center with time for $3.8 \mathrm{~cm}$ radius cylinder and the predicted damping in comparison to experimental data.

Figure 4 shows a series of grids that are used for the grid refinement study. The total number of cells are $40 \mathrm{~K}$, 256K, 1 Million and 4 Million. As a results, the capability in resolving the first natural mode has increased from 120 cells, to 200 cells, to 320 cells, and to 520 cells.

The mass center response to the initial inclined surface for different grids of $40 \mathrm{~K}, 256 \mathrm{~K}$ and $1 \mathrm{M}$ are shown in Figure 5. The slosh frequency is seen to be almost independent of grid resolution, as slosh frequency represents the bulk fluid motion. However, the finer mesh of $256 \mathrm{~K}$ gives less damping compared to the case of $40 \mathrm{~K}$ cells. The predicted damping values for different grids are listed in Table 1. One can clearly see that there is a significant accuracy increase in the predicted damping value in comparison to test data with using the finer mesh of $256 \mathrm{~K}$ : 
$0.312 \%$ vs. $0.334 \%$ (experimental data) (see Figure 5). The predicted damping value is nearly grid independent for $1 \mathrm{M}$ cells: $0.34 \%$ vs. $0.312 \%$ (256K). The CFD simulation captured the fundamental damping physics: viscous shear near wall and dissipation in fluid motion inside the tank. The present grid refinement study suggests that with an increase in tank size, a finer mesh will be required.
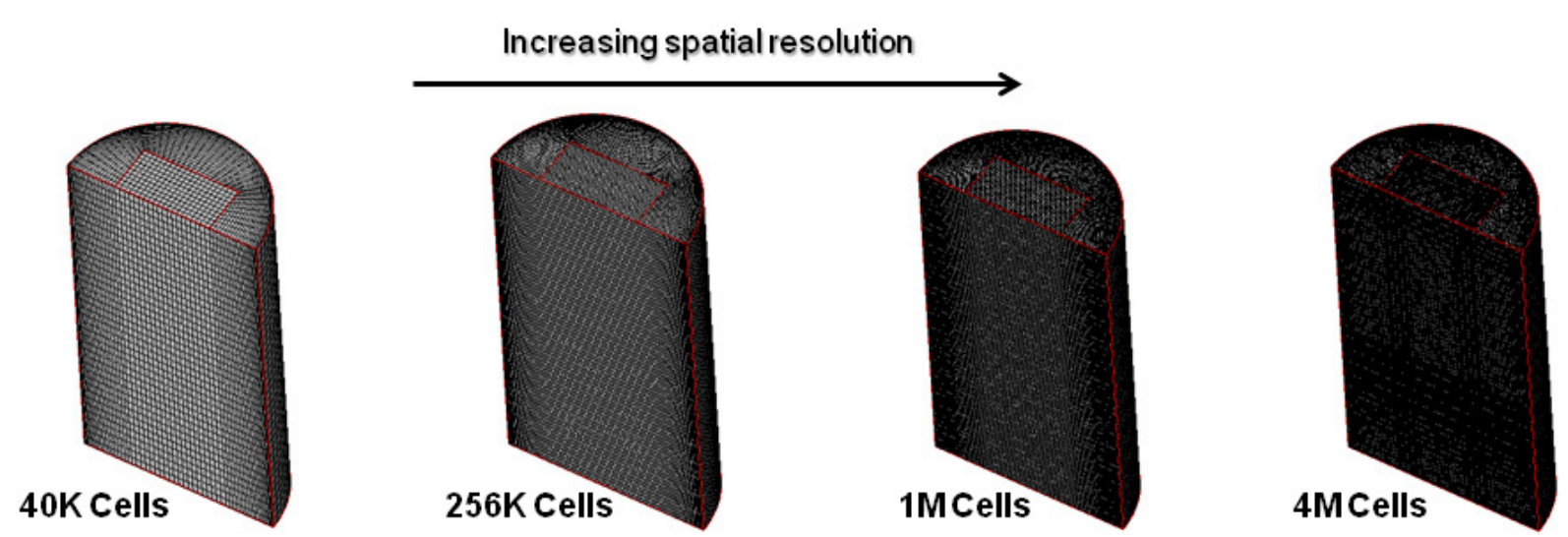

Figure 4. Models for computational grid refinement study.
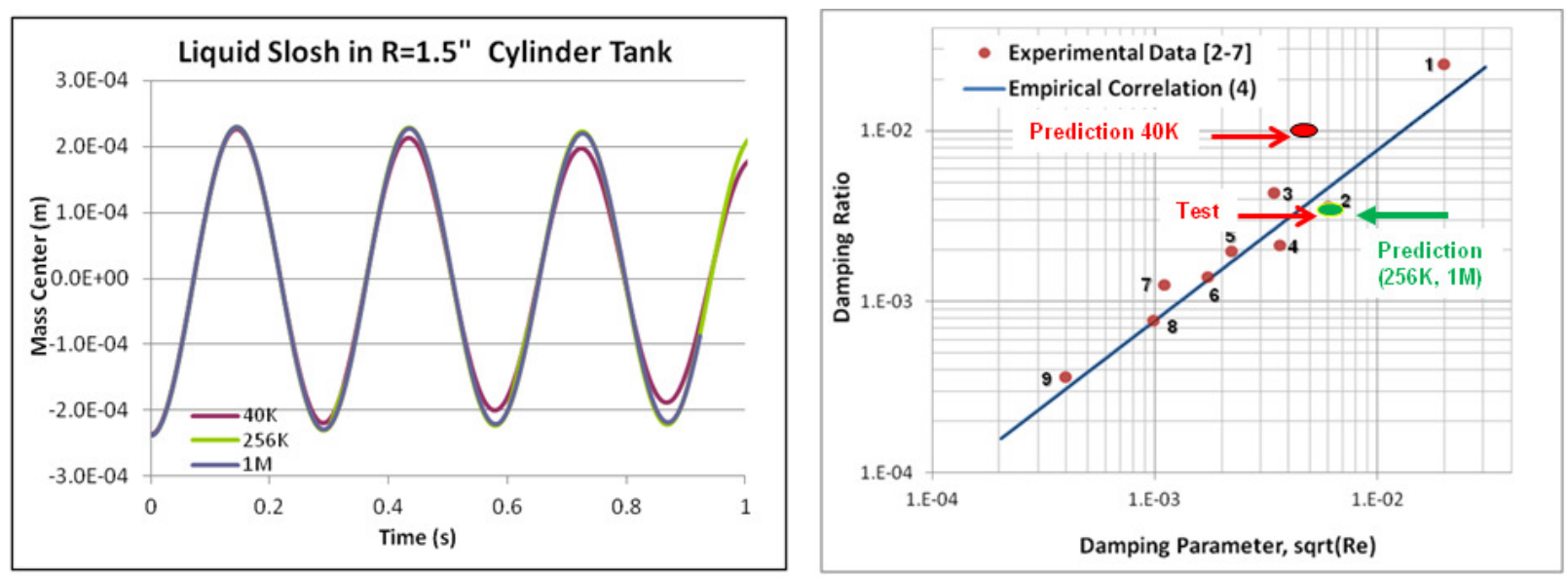

Figure 5. Effect of grid resolution on the slosh mass response and predicted slosh damping for a cylindrical tank of $3.8 \mathrm{~cm}(1.5$ ") radius.

Table 1 Grid Resolution Effects on Predicted Slosh Damping for $3.8 \mathrm{~cm}$ Radius Tank

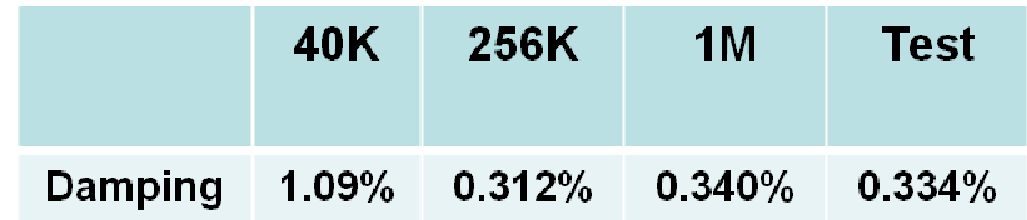

\section{$15.2 \mathrm{~cm}$ Radius Tank with Water}

Next we consider a tank that is $4 \mathrm{x}$ larger, i.e. $\mathrm{R}=15.2 \mathrm{~cm}$ (6"). We use the same grid and model as before, except that the geometry is scaled by $4 x$.

Given in Figure 6 is the mass center response to the initial inclined interface for different grids of 40K, 256K and $1 \mathrm{M}$ for this larger size tank. Due to the increase in tank radius, the slosh frequency has dropped. Here one observes the same trend: higher numerical damping for the coarse mesh of $40 \mathrm{~K}$ and nearly grid independent damping from

6

American Institute of Aeronautics and Astronautics 
256K and $1 \mathrm{M}$ cells. The predicted damping values for different grids are listed in Table 2. One notices almost 4 times higher damping from $40 \mathrm{~K}$ cells simulation indicating high numerical damping from the solution. The predictions using $256 \mathrm{~K}$ and $1 \mathrm{M}$ cells are very close to each other and to the experimental value. Based on the two sizes of tank, the correlation of equation (4) has been reproduced. This validation study builds confidence that CFD simulation can indeed well predict the small values of slosh damping.
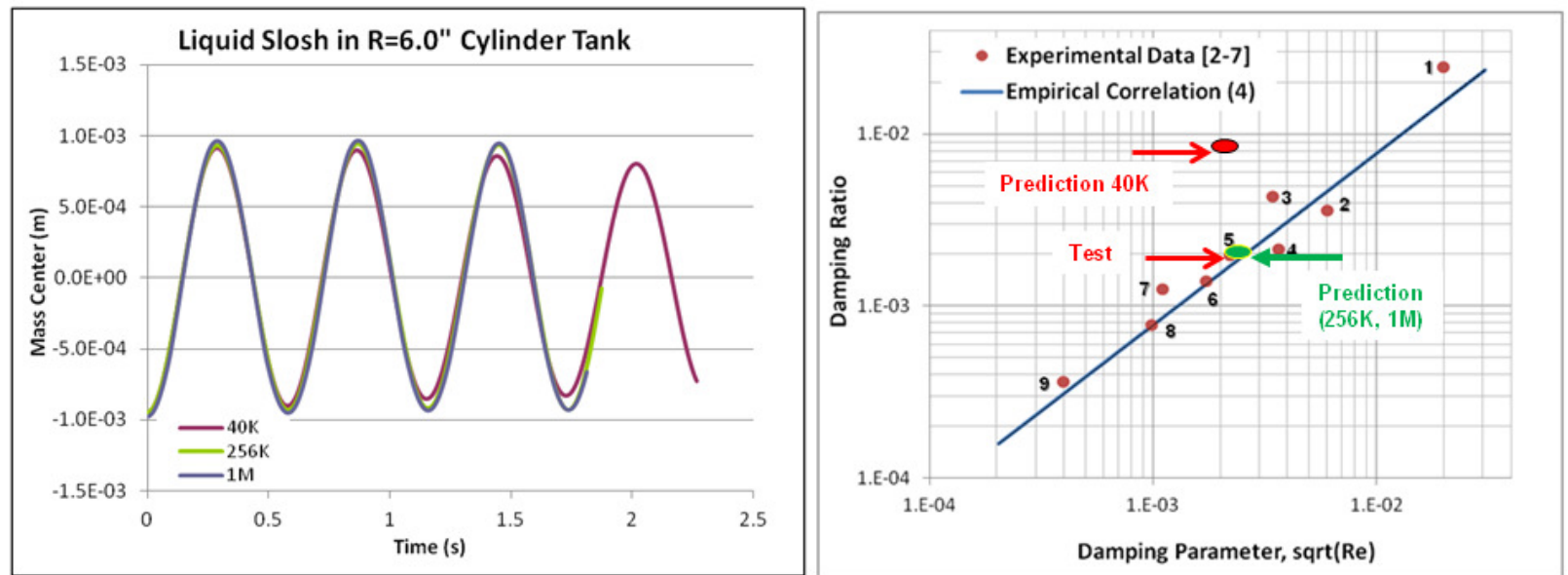

Figure 6. Effect of grid resolution on the slosh mass response and predicted slosh damping for a cylindrical tank of $15.2 \mathrm{~cm}(6 ")$ radius.

Table 2 Grid Resolution Effects on Predicted Slosh Damplng for $14.5 \mathrm{~cm}$ Radlus Tank

\begin{tabular}{|l|c|c|c|c|}
\hline & $40 K$ & $256 K$ & $1 M$ & Test \\
\hline Damping & $0.895 \%$ & $0.206 \%$ & $0.210 \%$ & $0.199 \%$ \\
\hline
\end{tabular}

\section{$45.7 \mathrm{~cm}$ Radius Tank with Water}

The next tank has a radius of $45.7 \mathrm{~cm}$ or 18 ". It is $12 x$ larger than the first tank $(3.8 \mathrm{~cm})$. During our study we found that as tank size increases, the second order spatial scheme has difficulty in convergence due to extremely low physical dissipation in the system, and one is forced to use the first order upwind. It is should be pointed out that even though the spatial scheme for velocity is $1^{\text {st }}$ order, the scheme for Volume-of-Fluid which tracks the gas-liquid interface is still second order accurate. As a result of the use of $1^{\text {st }}$ order upwind, the predicted damping values from $256 \mathrm{~K}$ or $1 \mathrm{M}$ cells are higher than the experiment data as observed from Figure 7 . However, with the use of increasing cell numbers from $40 \mathrm{~K}$, to $256 \mathrm{~K}$, to $1 \mathrm{M}$, and to $4 \mathrm{M}$, one can clearly see the reduction in the predicted damping. With $4 \mathrm{M}$ cells the predicted damping value is very close to the experimental data. The call for increased mesh density shows the need for a highly scalable CFD code which is under development. Table 3 lists the predicted damping value and comparison with the experimental data. 

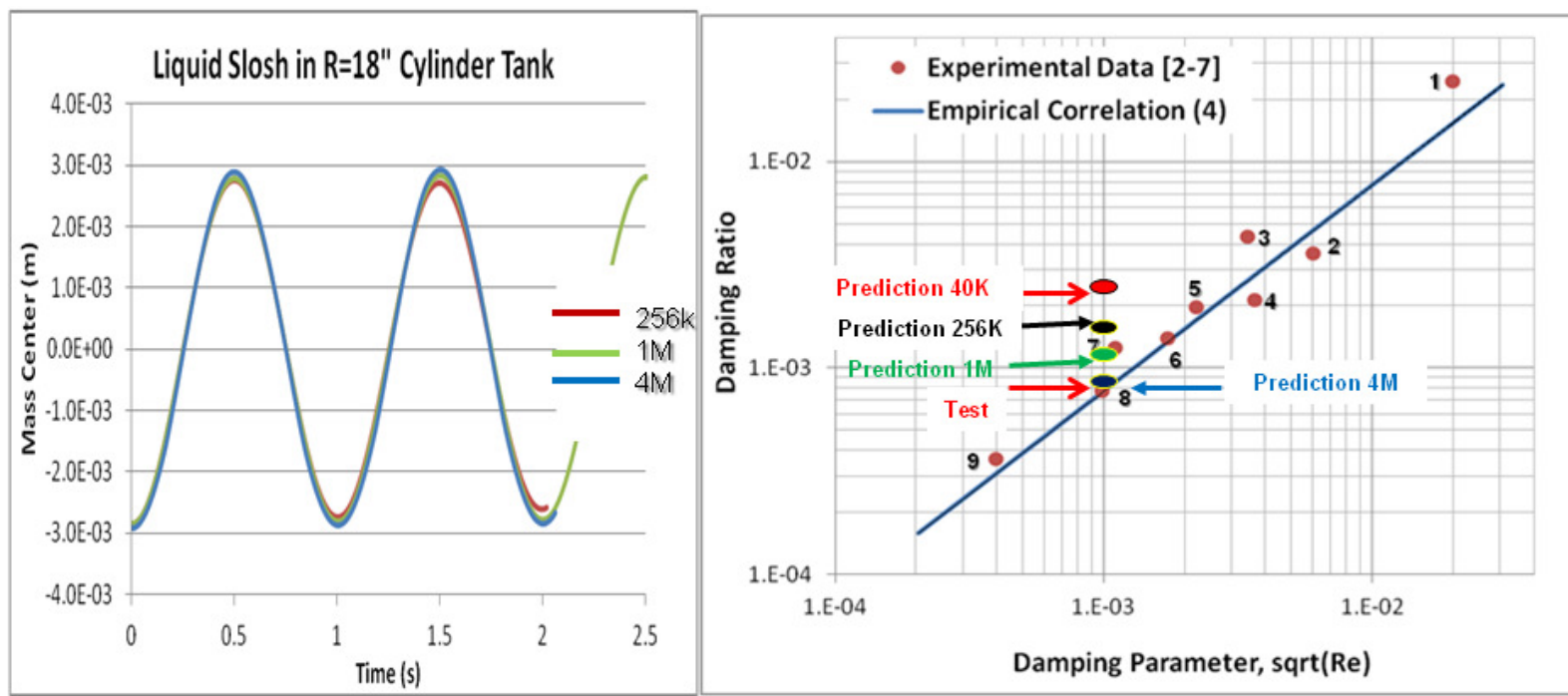

Figure 7. Effect of grid resolution on the slosh mass response and predicted slosh damping for a cylindrical tank of $45.7 \mathrm{~cm}$ radius

Table 3 Grid Resolution Effects on Predicted Slosh Damping for $45.7 \mathrm{~cm}$ Radius Tank

\begin{tabular}{|l|c|c|c|c|c|}
\hline & $40 K$ & $256 K$ & $1 M$ & $4 M$ & Test \\
\hline Damping & $0.438 \%$ & $0.162 \%$ & $0.140 \%$ & $0.0817 \%$ & $0.0776 \%$ \\
\hline
\end{tabular}

\section{Validation Study for Slosh Damping with Ring Baffle}

Based on the above validation study, one can see that damping caused solely by viscous effects in a smooth tank is quite small; especially for even a moderately large tank. Values of $\gamma$ are generally equal to 0.001 or less when the tank diameter is 1 meter or so. Guidance, Navigation and Control analysis usually requires $\gamma$ to be considerably larger than 0.01 for stable flight. Consequently, some method of increasing the damping is required. For axisymmetric tanks, a common method is to attach a series of ring baffles to the tank walls (see Figure 8). The baffles provide a substantial degree of damping when the free surface is near one of the baffles. The spacing between the baffles is chosen so that the damping exceeds the requirements, regardless of fill level.

Fuel-slosh damping by ring baffles in cylindrical tanks has been investigated extensively in the 1960's [13-18], both theoretically and experimentally. A survey of damping measurements obtained in various experiments shows many apparent discrepancies. With the above validation, the purpose of this study is to present a CFD approach for fuel-slosh damping which brings all of the results together and provides a logical basis for prediction of damping in full-scale tanks. 

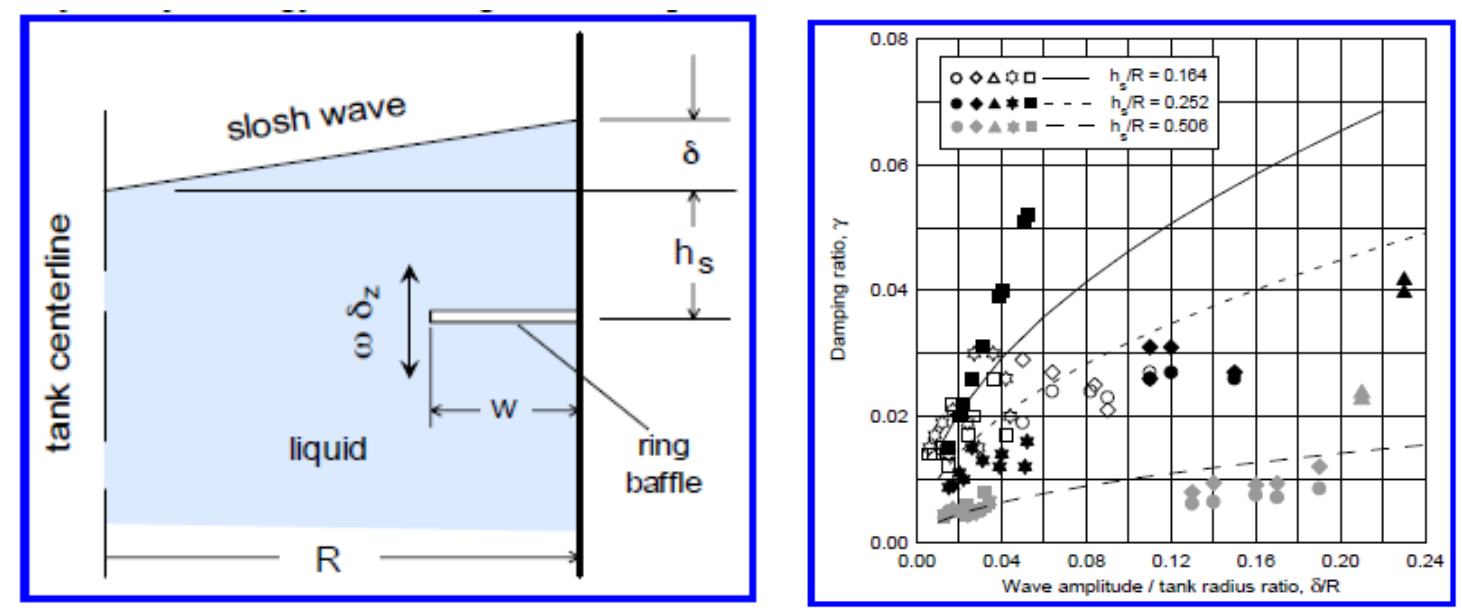

Figure 8. Schematic of ring baffle and damping in a cylindrical tank

The most widely used damping equation at present is the one obtained by Miles [17] which is based on experiments of Keulegan and Carpenter [18]. The equation is written as :

$$
\zeta=2.83 e^{-4.60 \mathrm{~d} / \mathrm{R}} \alpha^{(3 / 2)} \sqrt{\eta / \mathrm{R}}, \alpha \equiv \mathrm{A}_{\mathrm{B}} / \mathrm{A}_{\mathrm{T}}=2(\mathrm{w} / \mathrm{R})-(\mathrm{w} / \mathrm{R})^{2}
$$

Here, $d, w, A_{B}$, and $\alpha$ respectively denote the baffle depth, width, area, blockage ratio, while $\eta, R$, and AT denote the slosh wave amplitude, local tank radius, and tank cross-sectional area. O'Neill suggested that the wall side force amplitude (F) is easier to measure experimentally than $\eta$, and is linearly related the slosh wave amplitude in dimensionless form. Thus the following Miles-O'Neill equation is a convenient modification [14] .

$$
\bar{F} \equiv \mathrm{F} /(\operatorname{\rho gR} 3) \approx 1.71(\mathrm{n} / \mathrm{R}) \rightarrow \zeta=2.16 \mathrm{e}^{-4.60 \mathrm{~d} / \mathrm{R}} \alpha^{(3 / 2)} \sqrt{\bar{F}}
$$

Here, $\bar{F}, \rho$, and $\mathrm{g}$ are the dimensionless side force, the liquid density, and acceleration of gravity. Since $\mathrm{F}$ is also easier to measure than $\eta$ in CFD simulations as well, the above Miles-O'Neill form will be used to compare CFD results.

\section{Computational Model}

Two experimental sets were selected for comparison: the investigation of Silveira, Stephens, and Leonard [13] due to their measurement of slosh frequency shift, and that of O'Neill [14] due to his measurement of damping vs. dimensionless side force. Both sets include studies of slosh wave decay in cylindrical tanks and are outlined in [15].

A grid with a single baffle located at dimensionless height (h-d)/R $=1.25$ was initially used to develop the simulation. Subsequently, two grids were created with a single baffle located at (h-d)/R $=2.0$, where $d$ is the distance between baffle and the quiescent free surface, and $h$ is the free surface height (see Figure 10). This increased baffle height limits effects due to the tank bottom and is more consistent with experiments. The first grid has a baffle width ratio, $w / R=0.125(\alpha=0.234$, see equation (11)) while the second grid has $w / R=0.240(\alpha=$ $0.422)$.

Our previous grid refinement study found that at least four cells are needed along both the thickness and width of the baffle. To this end, a baffle thickness ratio of $t / R=1.5 \%$ was employed. While this is more than an order-ofmagnitude thicker than that usually used in practice $(\mathrm{t} / \mathrm{R} \sim 0.1 \%)$, the baffle thickness is generally not considered a critical parameter [16] and $\{t / R, t / w\}<1$. The hyperbolic tangent edge feature of the CFD-GEOM program was used to blend the grid spacing defined by the baffle thickness up to that defined by the top and bottom faces of the cylinder. These considerations led to grids of approximately $60 \mathrm{~K}$ cells.

Since ideal transverse slosh occurs only along a single axis (x), half-cylindrical domains were selected in order to reduce the required computation time. The boundary conditions employed are no-slip along the tank walls and baffle edges, and symmetry along the $\mathrm{xz}$ plane. The $\mathrm{w} / \mathrm{R}=0.125$ grid is illustrated in Figure 9 , while Figures 10 and 11 illustrate fluid motion in a typical simulation. The initial free surface with zero velocity is shown in Figure 10,

$$
9
$$

American Institute of Aeronautics and Astronautics 
followed by its progression along with velocity vectors at increments of approximately $0.1 \mathrm{sec}$ (along with velocity vector). In Figure 10, the liquid appears to be near a state of minimum velocity and maximum potential energy.
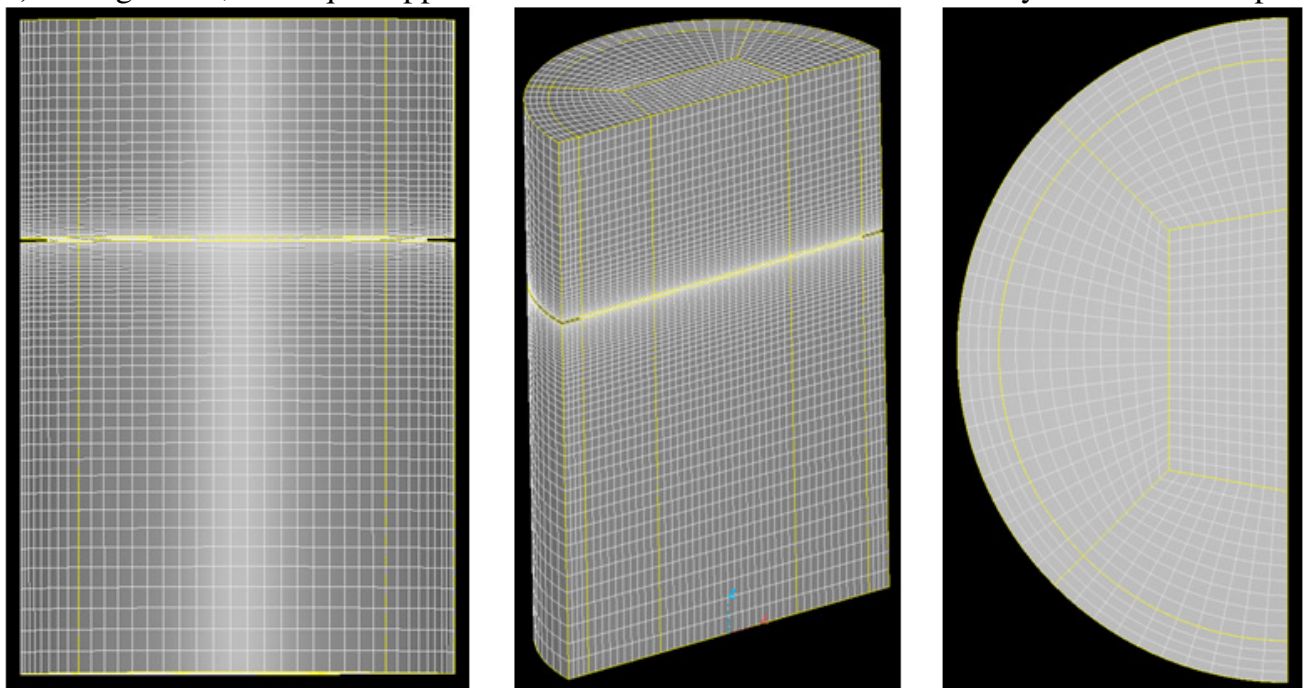

Figure 9. Computational Fluid Dynamics Model for a Tank with Internal Ring Baffle
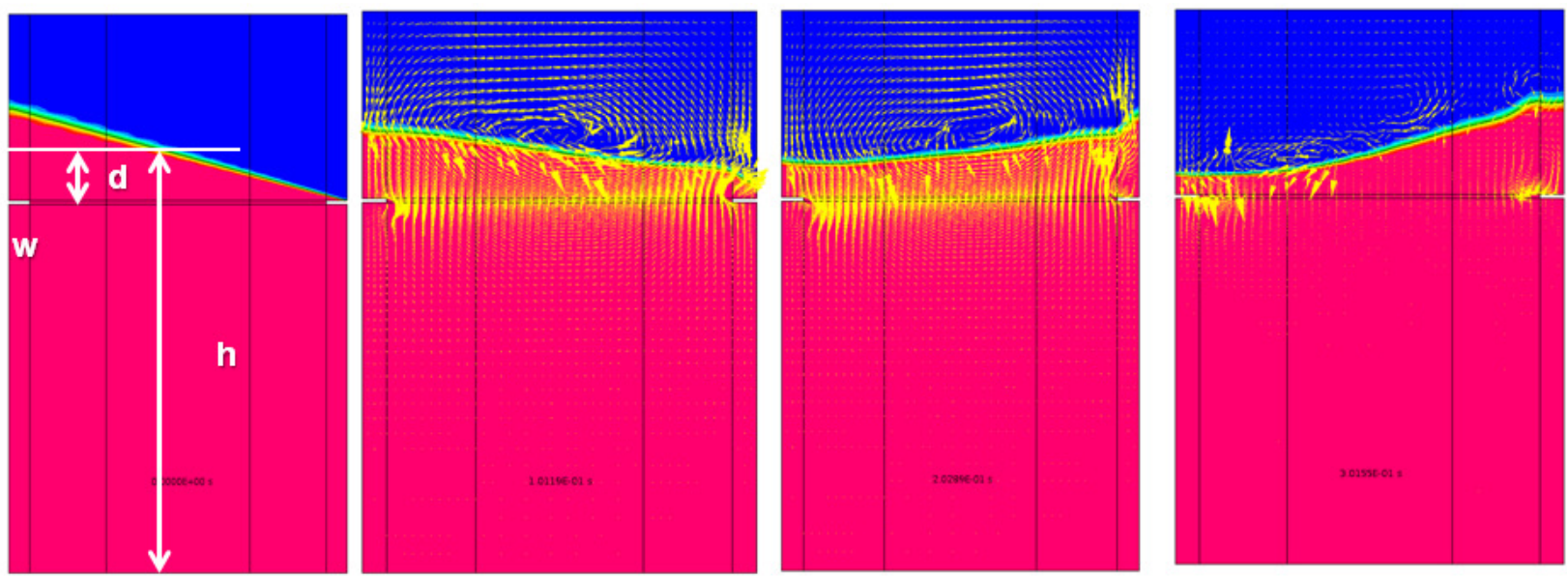

Figure 10. Progression of Free Surface and Fluid Velocity $(R=0.5 f t, w / R=0.125, d / R=0.25, t=0.0-0.3 s e c)$. 

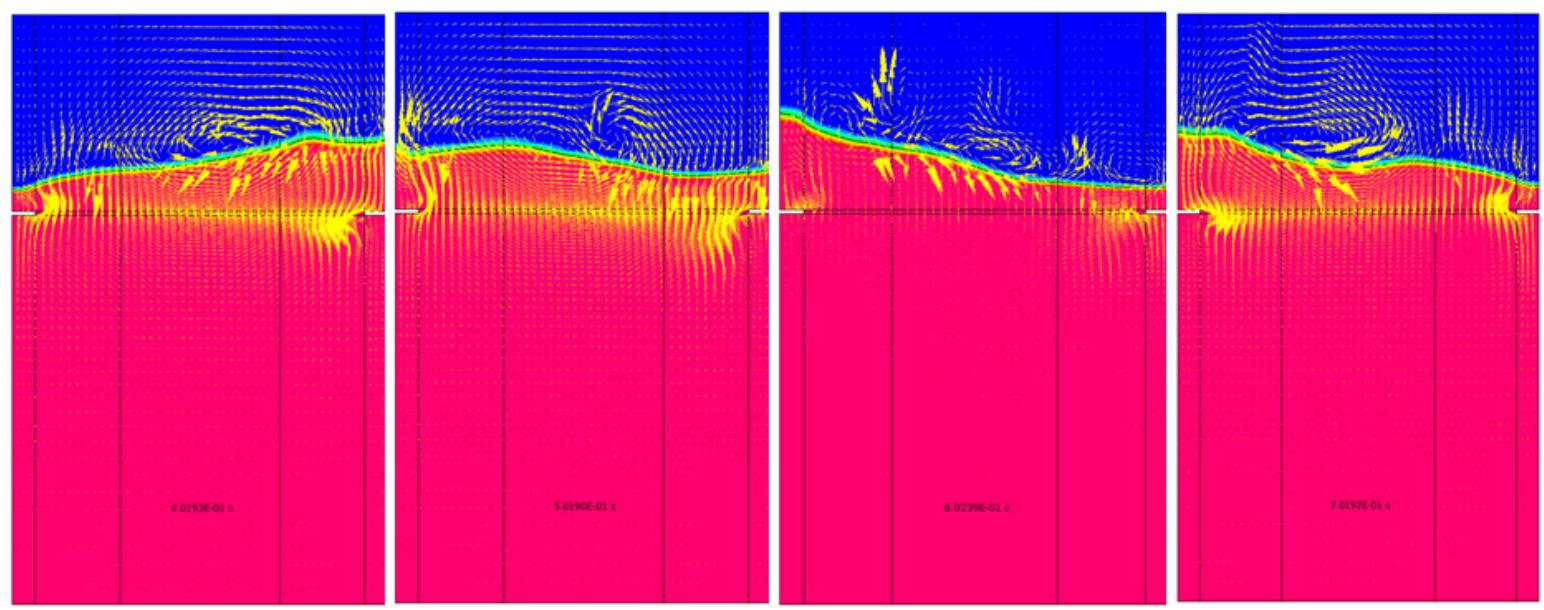

Figure 11. Progression of Free Surface and Fluid Velocity $(R=0.5 f t, w / R=0.125, d / R=0.25, t=0.4-0.7 \mathrm{sec})$.

Baseline Results

Simulations were first run with $\mathrm{R}=1.0 \mathrm{~m},(\mathrm{~h}-\mathrm{d}) / \mathrm{R}=1.25, \mathrm{w} / \mathrm{R}=0.15$, and $\mathrm{h} / \mathrm{R}=\{1.500,1.625,1.750,1.875$, $2.000\}$ corresponding to $d / R=\{0.250,0.375,0.500,0.625,0.750\}$. The initial air-water free surface was specified as before. Values of damping ratio were obtained as follows by fitting an exponential curve to five positive peaks of the fluid center-of-gravity position, $\mathrm{x}_{\mathrm{cg}}$ and using the decay constant, $\beta$.

$$
\mathrm{x}_{\mathrm{cg}, \max }=\Delta \mathrm{e}^{-\beta \mathrm{t}}=\Delta \mathrm{e}^{-\zeta \omega t} \rightarrow \zeta=\beta / \omega
$$

Center-of-gravity position data for $\mathrm{d} / \mathrm{R}=0.50$ is shown in Figure 12 . Results of damping ratio for all depth ratios are also shown in Figure 12 along with those predicted by the Miles-O'Neill Equation using the dimensionless side force of the middle (third) peak. As one can see the present CFD tool predicts the damping trend and value with baffle depth ratio fairly well.

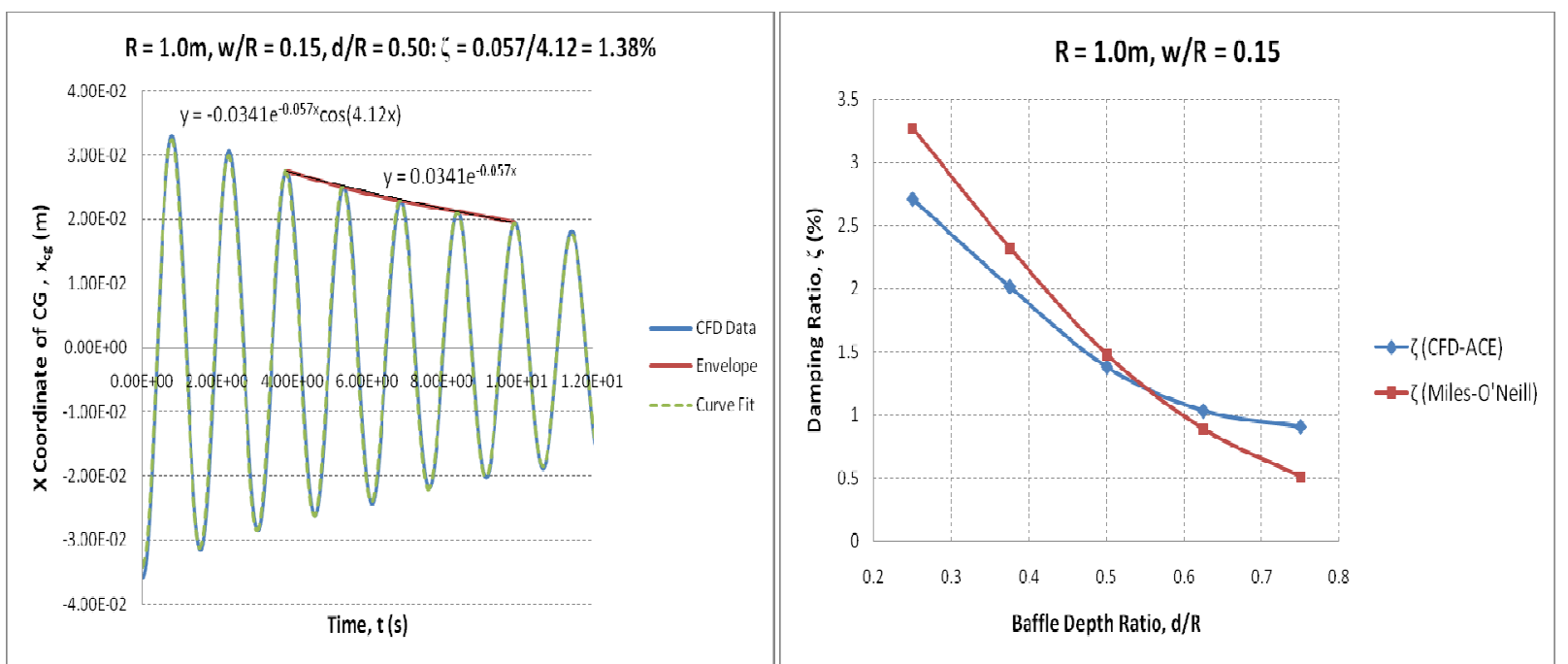

Figure 12. Computed force decay and damping for tank with baffle, and comparison with Mills-O'Neil

In the next simulation set, the number of cells was uniformly increased from $50 \mathrm{~K}$ to $75 \mathrm{~K}$ and simulations were run for $\mathrm{d} / \mathrm{R}=\{0.250,0.500,0.750\}$ only. The refined grid resulted in slightly lower values of damping ratio at each baffle depth ratio (2.7\% max reduction). Unlike the smooth tank, slosh damping due to the baffle is less sensitive to the grid resolution. 
For most simulations, the initial free surface slope was set to 0.2 . Whenever possible, the simulation was allowed to progress for 2.5 cycles before using cg position data so that the liquid could settle into a more normal sloshing motion than afforded by the linear-surface initial condition. To observe the effect of tank radius, simulations were first run with the w/R $=0.125$ grid scaled to $\mathrm{R}=\{0.25,0.50,1.00\} \mathrm{ft}$ with $\mathrm{d} / \mathrm{R}=0.25$. Since $\bar{F}$ can change rapidly at low depth ratios, values of the damping ratio are best compared with the Miles-O'Neill Equation by using the logarithmic decrement, $\delta$, with $\mathrm{n}=2$ as follows:

$$
\delta=2 \Pi \zeta=(1 / \mathrm{n}) \ln \left(\bar{F}_{i} / \bar{F}_{i+n}\right) \quad \rightarrow \quad \zeta_{\mathrm{i}}=\{1 /(4 \Pi)\} \ln \left(\bar{F}_{i-1} / \bar{F}_{i+1}\right)
$$

where $\mathrm{n}$ is the number of cycle observed. Thus, the Miles-O'Neill damping ratio at the $\mathrm{i}^{\text {th }}$ peak of $\mathrm{x}_{\mathrm{cg}}$ can be compared to the CFD value calculated from the $i-1$ and $i+1$ peaks. Results are shown in Figure 13 for $R=$ $\{0.25,0.50\} \mathrm{ft}$. Results for $\mathrm{R}=1.00 \mathrm{ft}$ are visually identical to those for $\mathrm{R}=0.5 \mathrm{ft}$ indicating that baffle damping is independent of Re for tanks of practical size, as suggested by the equation. Again one can see fairly good agreement with Miles' equation from the present CFD simulations.

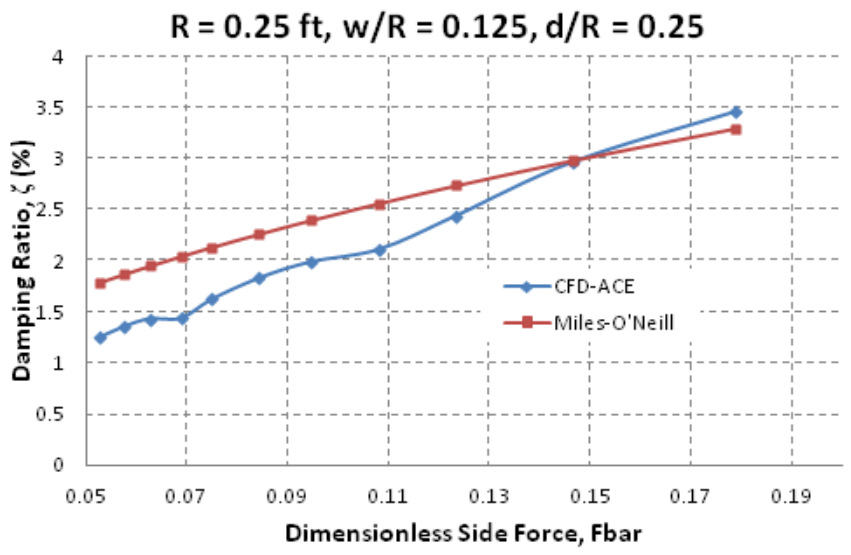

(a) Tank $R=0.25 \mathrm{ft}$

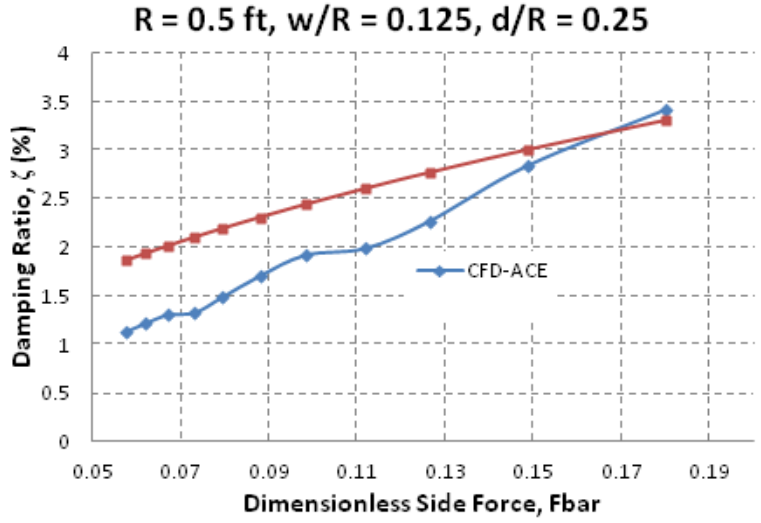

(b) Tank R=0.5 ft

Figure 13. Comparison of damping value predicted by CFD and that from empirical correlation of MilesO'Neil at tank with sizes of $R=0.25 \mathrm{ft}$ and $0.5 \mathrm{ft}$

\section{Effect of Baffle Location}

For the next set of tests, the $\mathrm{w} / \mathrm{R}=0.125$ baffle grid was again used to simulate sloshing, scaled to $\mathrm{R}=0.5 \mathrm{ft}$ with six different baffle depths below the free surface: $d / R=\{0.166,0.250,0.375,0.500,0.625,0.750\}$. Note that the smallest depth ratio is very close to that of the experimental data by O'Neil [14] (d/R =0.169). Data at $\bar{F}=0.15$ are conveniently calculated without extrapolation and shown in Figures 14 and 15 along with the Miles-O'Neill damping. These plots are presented in terms of $\delta$ for easy comparison with [13]. Selected experimental values from the reference have been extracted from [2] using the software, UN-SCAN-IT. The values have been scaled by a factor of 1.24 and included in Figures 14 and 15. This factor was selected so that the experimental $\delta$ for $d / R=0.285$, $\mathrm{w} / \mathrm{R}=0.241$ matches the intersection of the CFD and Miles-O'Neill curves at the same depth ratio for $\mathrm{w} / \mathrm{R}=0.240$. Data from [13] must be scaled because no value of $\bar{F}$ or $\eta$ is specified in the reference. It can be seen that when the baffle is close to the free surface it provides high damping. The present CFD simulation correctly predicts the trend and damping value in comparison to the experimental data. 


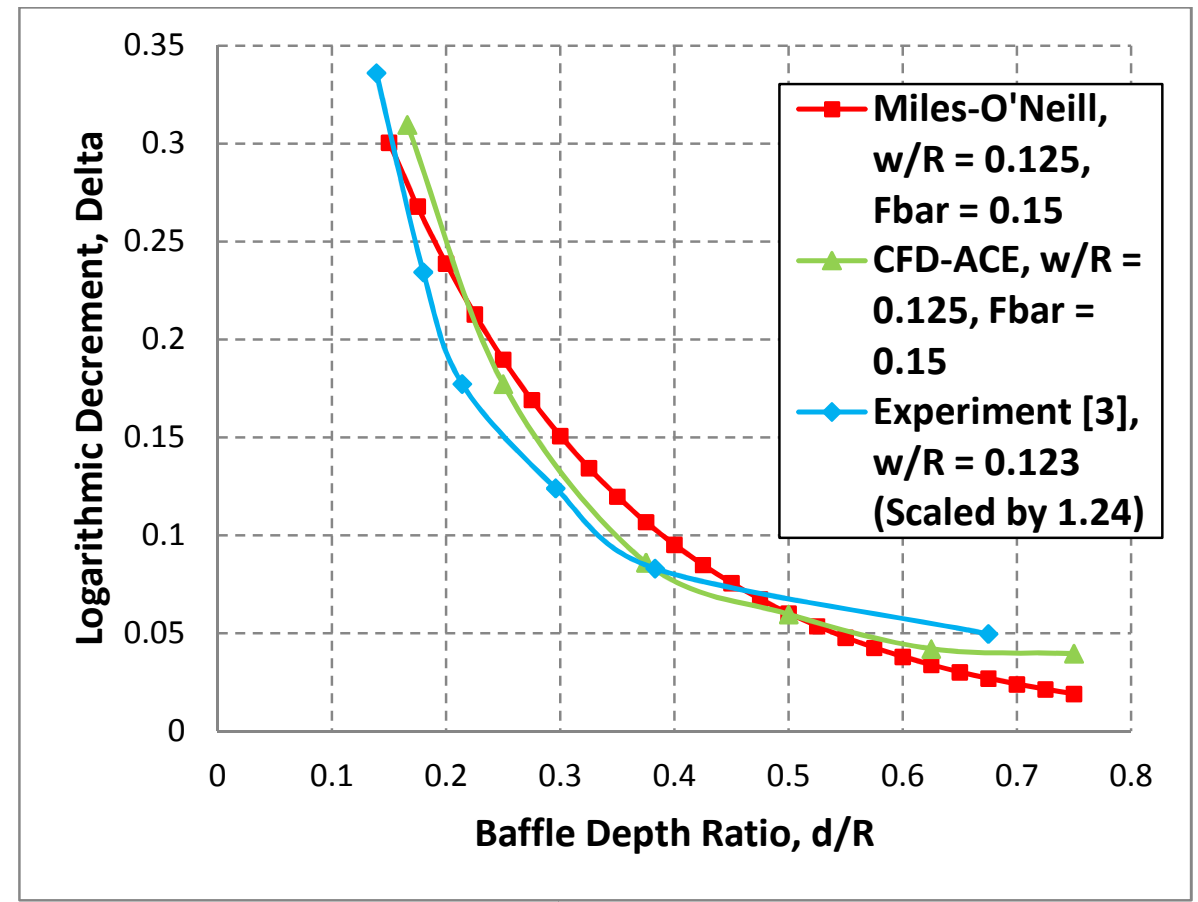

Figure 14. Effect of baffle depth ratio on the slosh damping for baffle width ratio w/R=0.125

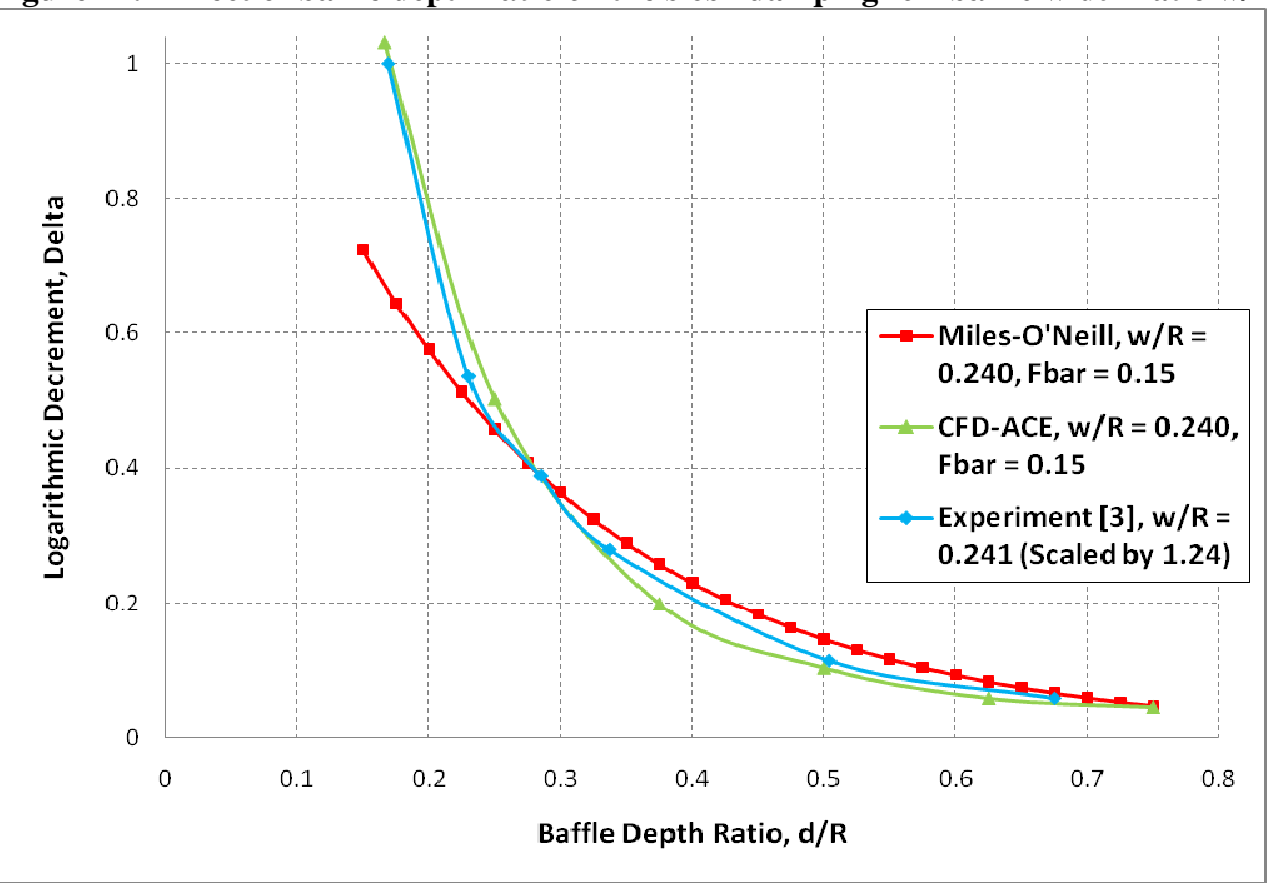

Figure 15. Effect of baffle depth ratio on the slosh damping for baffle width ratio $w / R=0.24$

\section{Conclusion}

The present study represented a continuing effort in validating CFD technology in modeling space vehicle propellant sloshing dynamics. This effort has clearly illustrated the soundness of the CFD approach in modeling the detailed fluid dynamics of tank sloshing and the excellent accuracy in extracting slosh mechanical properties, especially sloshing damping for smooth walls for different tank configurations and baffled tanks. The present study shows that CFD technology is especially applicable to the future design of propellant tanks, as there is no previous experimental data available for the same size and configuration. The previous analytical solutions are generally 13

American Institute of Aeronautics and Astronautics 
obtained for the linear analysis, where the amplitude of the slosh wave is small. CFD solution can go beyond the linear stability regime, and predict what will happen after surface breakup. CFD simulation also has no limitation on the gravitational acceleration, and can be applied to a realistic flight model.

Application of the CFD modeling tool has great potential in the design of propellant tank with multiple baffles. In general, the practice to estimate the total damping for multiple baffles is by a linear superposition of the estimated damping contribution from each individual baffle. This approach is considered adequate so long as the baffle separation distances exceeds their widths $(\mathrm{S}>\mathrm{W})$. However, experimental data involving multiple baffles are limited. CFD simulation could be used to determine the validity and applicability of such rules. Finally, CFD simulation could also be used to help develop a relation between slosh frequency and baffle parameters. Using baffles to shift frequency could be an alternative to tank compartmentalization.

\section{Acknowledgements}

This study was performed under a Task Order of the Jacobs Engineering NASA MSFC ESTS Contract NNM05AB50C. Dr. Ram Ramachandran was the Jacobs ESTS Task Lead, and Dr. Jeff West (MSFC Fluid Dynamics Branch, ER42) was the NASA MSFC Task Monitor.

\section{References}

1. H. Q. Yang and J. W. Peugeot, Propellant Sloshing Parameter Extraction from CFD Analysis, 46th AIAA/ASME/ASE/ASEE Joint Propulsion Conference \& Exhibit, July 25-28 2010, Nashville, TN. AIAA 20106889.

2. H. N. Abramson, "The dynamic Behavior of Liquids in Moving Containers", NASA SP-106, 1967.

3. J. W. Miles, MILES, " On the Sloshing of Liquid in a Cylindrical Tank. Rept. No. AM6-5, Gal-TR-18, The Ramo-Wooldridge Corp., Guided Missile Research Div., Apr. 1956.

4. K. M. Case, W. C. Parkinson, CASE, K. M., "Damping of Surface Waves in an Incompressible Liquid", J. Fluid Mech., vol. 2, part 2, Mar. 1957, pp. 172-184.

5. David Stephens, H. W. Leonard, and T. W. Perry, "Investigation of the Damping of Liquids in Right-Circular Cylindrical Tanks, Including the Effects of a Time-Variant Liquid Depth", NASA TN D-1367, 1962.

6. G. N. Mikishev and N. Y. Dorozhkin, 1961, An Experimental Investigation of Free Oscillations of a Liquid in Containers, Izv. Akad., Nauk SSSR, Otd. Tekh., Nauk, Mekh. I Mashinostr, 4, pp. 48-83.

7. Franklin Dodge, "the New Dynamic Behavior of Liquids in Moving Containers", the "new testament", 2000.

8. C. Dennehy, "Recent Experiences of the NASA Engineering \& Safety Center (NESC) GN\&C Technical Discipline Team (TDT)", AIAA-2007-6332, 2007.

9. CFD-ACE+, Version 2009.0, User Guide, ESI-CFD Inc., Huntsville, AL, 2009

10. H. Q. Yang, J. M. Rojahn, J. W. Peugeot, D. J. Dorney. CFD Analysis of Propellant Tank sloshing under Vertical Oscillatory Thrust and Horizontal Oscillatory Side Load, JANNAF 2008, Paper LPS-06, Feed System Design and Analysis, Orlando, November 10-13, (2008).

11. H. Q. Yang and J. W. Peugeot, Propellant Sloshing Parameter Extraction from CFD Analysis, 46th AIAA/ASME/ASE/ASEE Joint Propulsion Conference \& Exhibit, July 25-28 2010, Nashville, TN. AIAA 20106889 .

12. H. Q. Yang and J. W. Peugeot, Surface Instability of Liquid Propellant under Vertical Oscillatory Forcing, 47th AIAA/ASME/ASE/ASEE Joint Propulsion Conference \& Exhibit, July 31-August 3,2011, San Diego, CA. AIAA 2011-5773.

13. Silveira, Stephens, and Leonard, "An Experimental Investigation of the Damping of Liquid Oscillations in Cylindrical Tanks with Various Baffles", NASA TND-717, May, 1961

14. O'Neill, J.P., "Final Report on an Experimental Investigation of Sloshing", STL/TR-59-0000-09960, Space Tech. Lab., Inc., July, 1956

15. Stricklin and Baird, "A Survey of Ring Baffle Damping in Cylindrical Tanks", NASA TN-R185, April, 1966

16. NASA Space Vehicle Design Criteria (Structures): "Slosh Suppression", NASA SP-8031, May, 1969.

17. J. W. Miles," Ring Damping of Free Surface Oscillations in a Circular Tank", J. Appl. Mech., vol. 25, no. 2, June 1958, pp. 274-276.

18. G. H. Keulegan; L. H. Carpenter, "Forces on cylinders and plates in an oscillating fluid", Journal of Research of the National Bureau of Standards 60 (5): 423-440, 1958.

14

American Institute of Aeronautics and Astronautics 